Jurnal Pengajian Melayu - JOMAS, Jilid 32(1), 2021: 49-68

\title{
PENGARUH TURKI TERHADAP SOSIO-BUDAYA DUNIA MELAYU
}

\author{
(TURKISH INFLUENCE ON SOCIO-CULTURE OF THE MALAY WORLD)
}

\author{
Marzudi Md Yunus \\ marzudi@um.edu.my \\ Universiti Malaya, Kuala Lumpur \\ Malaysia
}

Received: 8 February 2021; Accepted: 8 April 2021

\begin{abstract}
Turkey is the heir to the Ottoman Islamic Caliphate, extending significant influence on Muslims worldwide. All aspects of the Turkish socio-culture will, directly and indirectly, influence the socioculture of Muslims. This situation also applies to Muslims in Malaysia, specifically Malays. The influences range from political and administrative to cultural and artistic, and even the way of thinking. Research and analysis conducted towards the writings and historical texts proved that Turkish influence exists in the Malay world. For example, there is a Malay state administration modelled from the Ottoman Caliphate to advance it to synchronise with modern changes in the West. During the 1930s, Turkey's modernisation drew Malay intellectuals' attention, spreading the ideas through writing in newspapers and magazines. Developments in Turkey exposed the Malays to various polemics resulting from Kemal's modernisation and secularisation when he led the Turkish government. For Malays, events in Turkey serve as lessons in their effort to develop their community towards progress in all aspects. Development in Turkey has also attracted various newspapers and magazines like 'Pengasoh', 'Al-Ikhwan', 'Malaya', 'Majalah Guru', 'AlHedayah', 'Bahtra' and 'Saudara'. They celebrated Kemal establishing the Turkish republic and its various modernisation plans. Turkish influence was also pervasive in filmmaking, therefore, proving developments in Turkey influence various aspects of the Malay world. For Malays, events in Turkey serve as lessons and examples towards charting its progress in all aspects.
\end{abstract}

Keywords: Turkey, Malay, Socio-Culture, Culture, Civilisation, Art. 


\begin{abstract}
Abstrak
Turki adalah negara pewaris kerajaan Khalifah Islam Uthmaniyyah yang mempunyai pengaruh yang besar kepada umat Islam di seluruh dunia. Segala aspek sosiobudaya Turki secara langsung dan tidak langsung akan mempengaruhi sosiobudaya umat Islam. Keadaan ini turut berlaku terhadap umat Islam di Malaysia, khususnya kepada orang Melayu. Pengaruh-pengaruh tersebut meliputi aspek politik, pentadbiran, kebudayaan, kesenian, malah turut merangkumi aspek pemikiran. Penelitian dan analisis kandungan yang dilakukan terhadap penulisan dan teks sejarah membuktikan bahawa memang wujud pengaruh Turki di dunia Melayu. Dalam aspek politik dan pentadbiran, terdapat negeri Melayu yang mengambil model pentadbiran Khalifah Uthmaniyyah untuk memajukan sistem pentadbiran negeri untuk menyelaraskan dengan perubahan moden yang berlaku di dunia barat. Pada 1930-an, pemodenan di Turki menarik perhatian golongan cendekiawan Melayu menyebarkan idea pemodenan melalui penulisan surat khabar dan majalah. Perkembangan yang berlaku di Turki mendedahkan orang Melayu kepada pelbagai polemik yang terhasil akibat proses pemodenan dan pensekularan yang dilaksanakan oleh Kemal sejak menerajui pemerintahan Turki. Bagi orang Melayu, peristiwa yang terjadi di Turki itu boleh dijadikan pengajaran dan tauladan dalam usaha membangunkan orang Melayu ke arah kemajuan dalam segenap aspek. Perkembangan yang sedang rancak berlaku di Turki telah menarik minat beberapa akhbar dan majalah seperti Pengasoh, Al-Ikhwan, Malaya, Majalah Guru, Al-Hedayah, Bahtra dan Saudara yang meraikan kejayaan Kemal menubuhkan Republik Turki serta pelbagai rancangan pemodenan yang telah dijalankan bagi membangunkan Turki menjadi sebuah negara moden. Pengaruh Turki jika turut meresap dalam bidang perfileman yang jelas menunjukkan bahawa perkembangan di Turki mempengaruhi sosio-budaya tempatan dalam pelbagai aspek dunia Melayu. Bagi orang Melayu, peristiwa yang terjadi di Turki itu boleh dijadikan pengajaran dan tauladan dalam usaha membangunkan orang Melayu ke arah kemajuan dalam segenap aspek.
\end{abstract}

Kata Kunci: Turki, Melayu, sosiobudaya, Kebudayaan, Tamadun, Kesenian.

\title{
Pendahuluan
}

Masyarakat Melayu memandang tinggi kepada daulah Turki Uthmaniyyah berdasarkan kepada penghormatan dan penghargaan yang diberikan kepada daulah tersebut. Masyarakat Melayu di Semenanjung Tanah Melayu dan Nusantara menganggap 'Raja Rom' sebagai seorang raja yang agung dan kuat. Sejak abad ke-16, penghormatan ini diberikan secara khusus kepada Sultan Turki Uthmaniyah selaku penaung kerajaan Islam yang besar ketika itu dan peranan mereka sebagai pendukung khilafah Islam. Karya-karya kesusasteraan Melayu tradisional menggambarkan daulah Turki Uthmaniyyah sebagai sebuah kerajaan Islam yang hebat dan kuat (Ermy Azziaty, 2016).

Ketinggian tamadun suatu bangsa akan mempengaruhi bangsa-bangsa lain di persekitaran kawasan negara terbabit. Bangsa-bangsa yang kurang maju akan cuba meniru dan bersaing untuk mencapai kemajuan yang setara atau lebih baik berbanding dengan bangsa yang dijadikan rujukan (Ralph Patrick, 1963). Perkara tersebut merupakan suatu yang lazim dalam peradaban manusia sejagat. Manusia sentiasa berlumba atau bersaing antara mereka dalam perkara yang melibat urusan hidup di dunia. Oleh yang demikian, wujudlah fenomena pengaruh-mempengaruhi dalam setiap usaha manusia memperbaiki teknologi, gerak kerja dan falsafah hidup mereka (Ralph Patrick, 1963). Segala urusan yang dinyatakan itu merangkumi urusan politik, pentadbiran, ekonomi, sosial dan sistem kepercayaan manusia. 
Turki moden pada hari ini adalah kesimbungan daripada kerajaan Islam Uthmaniyyah yang mula berkembang semenjak pertengahan abad ke-15 setelah jatuhnya kerajaan Byzantium (constantinopel), iaitu pada tahun 1453 oleh Sultan Muhammad Al-Fatih. Nama kerajaan Uthmaniyyah ini diasaskan dan dibangsakan kepada Sultan Osman Bin Sauji Bin Artugrul Bin Sulaiman Syah Bin Kia Alp, iaitu ketua kepada kabilah Kabi di Asia Tengah sejak tahun 1288 Masihi atau 687 Hijrah (Hamka, 2016). Kegemilangan Kerajaan Uthmaniyyah dalam sistem kekhalifahan umat Islam terus berlangsung dengan pengaruh yang kuat terhadap seluruh dunia Islam termasuklah Tanah Melayu. Kerajaan kesultanan Johor juga mempunyai hubungan dengan kerajaan Uthmaniyyah sebelum kejatuhan empayar Islam tersebut (Abd Jalil, 2011). Negeri-negeri Melayu yang lain juga dikatakan mempunyai hubungan secara langsung dengan kerajaan Islam Uthmaniyyah Turki, dengan penghantaran ramai ulama-ulama daripada kerajaan Uthmaniyyah sebagai penasihat agama kepada sultan-sultan di Alam Melayu (Hamka, 2016).

Bawah sistem khalifah, pemimpin yang digelar sebagai khalifah merupakan ketua umat Islam yang berperanan menjadi pengganti Nabi Muhammad SAW bagi memimpin seluruh umat Islam. Khatifah Kerajaan Uthmaniyyah yang berpusat di Istambul ketika itu merupakan sumber rujukan dan mempunyai pengaruh besar kepada dunia Islam. Ketua-ketua kerajaan Islam seluruh dunia telah datang ke Istanbul untuk mendapatkan pengiktirafan sebagai ketua dan mendapat perkenan bagi menggunakan geraran sultan (Hamka, 2016; Kadi, Wadad, Shahin dan Aram, 2013). Pada ketika ini hubungan dan pengaruh secara langsung telah berlaku antara kerajaan Islam di seluruh dunia. Namun selepas kejatuhan pemerintahan khalifah Uthmaniyyah, hubungan secara langsung telah terputus. Perkara ini pula diburukkan lagi dengan penjajahan negara-negara umat Islam oleh kuasa-kuasa barat.

Kejatuhan kerajaan Islam Uthmaniyyah (Khalifah) pada tahun 1922 bermulanya terputusnya hubungan secara langsung dengan seluruh kerajaan Islam diluar Turki (Jay Shaw, 1977). Turki moden yang berasaskan sekularisme telah membawa perubahan yang cukup drastik kepada negara tersebut. Namum perubahan tersebut tidak menghalang kepada terhentinya pengaruh Turki kepada negara-negara Islam lain termasuk Tanah Melayu. Pemodenan Turki dalam pentadbiran dan sosial turut menjadi perhatian kepada dunia Islam secara amnya. Tambahan pula, perkembangan politik Turki pada masa ini telah memberikan suntikan pengaruh baharu kepada parti-parti politik di Malaysia (Abdar Rahman, 2017).

\section{Sorotan Kajian}

Muhammad, Mohd Shazwan \& Mohd Samsudin (2016) menjelaskan bahawa Konflik Perang Dunia Pertama (PD1) yang telah berlaku pada 28 Julai 1914 tidak harus diketepikan dalam pensejarahan Malaysia. Walaupun peperangan tersebut secara fizikalnya meletus di Eropah, namun kesannya turut dirasai oleh negara-negara di seluruh dunia termasuklah Tanah Melayu. Sebagai negerinegeri jajahan dan naungan British, Tanah Melayu turut menerima kesan daripada konflik PD1 yang terbahagi kepada dua pihak, iaitu Kuasa Bersekutu dan Kuasa-kuasa Pusat. Sebelum PD1 meletus, pentadbiran British di negeri-negeri Melayu mempunyai hubungan yang baik dengan Jerman dan Turki, malah konsul Jeneral bagi negara Jerman, Turki dan Austria Hungary telah dilantik untuk menjaga kepentingan warganegara masing-masing. Walau bagaimanapun, apabila PD1 meletus yang melibatkan peperangan British dan sekutunya dengan Jerman, Turki, Austria- 
Hungary dan Bulgaria, British sedar kolonialisme British di negeri-negeri Melayu harus terus diperkukuh. Kebimbangan ini adalah disebabkan masih terdapatnya pengaruh daripada musuhmusuh British ke atas penduduk Negeri-negeri Melayu Bersekutu. Kebimbangan British ini berasaskan kepada wujudnya hubungan secara langsung raja-raja Melayu dengan dengan Empayar Turki-Uthmaniyyah di Istanbul. Berikutan dengan itu, British telah memperkukuhkan kolonialisme terhadap Negeri-Negeri Melayu Bersekutu pada zaman PD1 dengan penggubalan enakmen kecemasan, iaitu "The Public Emergency Enacment, 1914" (TPEE) bagi mengekang pengaruh negara musuh, terutamanya Jerman dan Turki Uthmaniyyah. Enakmen ini meletakkan NegeriNegeri Melayu Bersekutu berada sepenuhnya di bawah kawalan British pada zaman perang.

Perubahan besar, iaitu kejatuhan kerajaan Uthmaniyyah turut mendapat perhatian orang Melayu di Tanah Melayu. Walaupun kepatuhan dan ketaatan orang Melayu ketika itu masih tertumpu kepada raja-raja Melayu, namun minat orang Melayu terhadap peristiwa yang berlaku di Dunia Islam khususnya di Timur Tengah tidak pernah pudar. Orang Melayu bukan sahaja menunjukkan minat yang mendalam terhadap peristiwa kenaikan Kemal dan kejatuhan pemerintahan khalifah, tetapi pada masa yang sama juga menunjukkan minat yang tinggi terhadap pelbagai pembaharuan yang dilaksanakan oleh Kemal bawah rancangan pemodenannya. Keadaan tersebut menarik minat akhbar dan majalah Melayu untuk membuat liputan yang meluas berkenaan isu-isu tersebut. Keadaan ini telah menimbulkan polemik dan wacana terbuka antara akhbar dan majalah Melayu tersebut khususnya berkenaan pelbagai pembaharuan yang dijalankan oleh Kemal sejak memimpin Turki menjadi sebuah republik. Akhbar dan majalah Melayu juga tidak terkecuali daripada membincangkan pelbagai polemik yang berlaku akibat pembaharuan yang dijalankan oleh Kemal di Turki. Mereka juga telah menunjukkan kecenderungan, minat dan kebimbangan yang ketara dalam menyiarkan pelbagai berita dan rencana berkaitan pembaharuan yang dijalankan oleh Kemal sekitar tahun 1920-an. Antara isu yang sering menjadi polemik dalam akhbar dan majalah Melayu adalah berkenaan undang-undang yang mewajibkan pemakaian pakaian ala Barat, penggunaan tulisan Latin menggantikan tulisan Arab, terjemahan dan tafsiran al-Quran dalam bahasa Turki, pemansuhan pelbagai ajaran Islam yang dianggap lapuk dan rancangan emansipasi wanita Turki (hak politik mahupun persamaan darjat). Mereka berpendapat bahawa peralihan daripada unsur tradisi Islam kepada pembaratan adalah sebahagian daripada permodenan yang harus diikuti jika inginkan kemajuan sepertimana dunia barat (Abu Hanifah Haris \& Mohammad Redzuan, 2011).

Pada tarikh 3 Mac 1924, Khilafah Uthmaniyyah telah dijatuhkan secara rasmi oleh Mustafa Kemal Ataturk. Bermulalah pewartaan pemerintahan negara yang diasingkan dengan agama. Mahkamah-mahkamah syariah juga telah ditutup malahan jawatan Menteri Syariah dan Menteri Auqaf turut dihapuskan. Lebih menyedihkan apabila Khalifah Abdul Majid II yang merupakan khalifah terakhir kerajaan Islam Uthmaniyyah, telah dihalau keluar dari Turki bersama-sama ahli keluarganya. Kejatuhan khilafah Uthmaniyyah telah meninggalkan kesan yang amat buruk terhadap umat Islam. Antara kesannya adalah umat Islam hilang tempat bergantung, kerana kewujudan khalifah adalah umpama wujudnya penjaga terhadap umat Islam. Namun, setelah sistem khalifah dihapuskan umat Islam (di seluruh dunia) hidup dalam keadaan huru-hara dan ditindas tanpa belas kasihan. Mereka hidup tanpa ada pembelaan daripada pemimpin tertinggi Islam. Umat Islam tidak mampu melawan kuasa besar Barat. Mereka sekadar mendapat simpati tetapi tidak diempati (Siti Ainum, 2020).

Di samping itu, kesan yang paling ketara setelah kejatuhan Khilafah Uthmaniyyah adalah berlakunya perpecahan ummah. Sebelum wujudnya negara bangsa, kerajaan Islam disatukan di bawah satu pemerintahan khalifah, dengan setiap kawasan pula ditadbir oleh gabenor atau sultan 
yang mempunyai hubungan dengan Khalifah Uthmaniyyah di Istambul. Perancangan Barat untuk menyerang Kerajaan Turki-Uthmaniyyah menerusi Perang Dunia Pertama telah mengakibatkan satu persatu wilayah Islam dikeluarkan dari pemerintahan khalifah. Hal ini berlaku kerana, perpaduan umat Islam boleh menggugat kuasa Kristian Barat. Lalu, mereka mengadakan satu pakatan untuk memecah-belahkan umat Islam dengan menjadikan mereka berpuak-puak dan mempertahankan kepentingan bangsa masing-masing secara berasingan. Kejatuhan Khalifah Uthmaniyyah berlaku akibat ideologi sekular yang dibawa oleh Barat yang hakikatnya tidak membawa umat Islam ke arah kebaikan. Pinjaman wang dengan bank Yahudi untuk membina Terusan Suez telah meninggalkan kesan buruk yang berpanjangan terhadap umat Islam. Sikap mengagungkan budaya Barat ini telah menjadi punca kejatuhan kerajaan Islam Uthmaniyyah. Status Islam telah diturunkan darjatnya sebagai agama Ilahi yang serba komprehensif kepafa agama ritual yang terpinggir di sisi masyarakat Islam (Siti Ainum, 2020).

Sehari selepas umat Islam meraikan sambutan Isra' dan Mikraj pada 1342H, iaitu pada 28 Rejab 1342H (3 Mac 1924M), sistem kekhalifahan Islam telah berakhir ekoran pembubaran Khilafah Othmaniyah oleh kelompok sekular di Turki. Pembubaran sistem khalifah memberi kesan yang sangat besar kepada keseluruhan aktiviti umat Islam di seluruh dunia. Kesan segera kejaatuhan khalifah membangkit kesedaran para ulamak untuk memacu semula kebangkitan Islam melalui penubuhan gerakan-gerakan Islam di serata dunia. Di dunia Arab, yang paling terkenal ialah Ikhwanul Muslimin yang ditubuhkan pada 1928M, di Afrika Barat muncul Hizbul Istiqlal di Maghribi pada 1937M, Jamaat Islami di India pada 1941, Majlis Syura Muslimin Indonesia (Masyumi) di Indonesia pada 1943M dan Hizbul Muslimin di Tanah Melayu pada 1948M (Mohd Fadli, 2019).

Mohd Fadli(2019) menjelaskan kejatuhan Daulah Othmaniyah itu sendiri akibat pembaratan yang dimulakan oleh Sultan Mahmud II (1808-1832M) sejak 1820-an, yang membawa kepada penyebaran fahaman sekular dan akhirnya mereka menjatuhkan Sultan Abdul Hamid II (18761909M) pada 27 April 1909M. Kejatuhan Sultan Abdul Hamid II ini telah menyebabkan berlakunya proses sekularisasi secara rasmi dalam Daulah Uthmaniyah, sehingga Sheikhul Islam Uthmaniyah, Sheikh Mustafa Sobri Effendi (1869-1954M) mengingatkan tentang bahaya pemisahan politik daripada agama akan menjadi jalan singkat yang memurtadkan umat Islam. Pada sudut yang lain pula, kejatuhan Sultan Abdul Hamid II sebenarnya telah membangkitkan seorang ulamak, Sheikh Darwish Vehdati al-Hafiz yang menubuhkan sebuah gerakan Islam di Istanbul, Ittihad alMuhammadi pada tahun 1909 untuk mengembalikan Islam sebagai dasar negara, tetapi beliau dihukum gantung kerana dituduh cuba menjatuhkan khalifah (Mohd Fadli, 2019).

Empat hari selepas Khilafah Othmaniyah dibubarkan, para ulamak Universiti al-Azhar mengisytiharkan tindakan Mustafa Kamal Atarturk itu sebagai tidak sah. Terdapat pula beberapa usaha daripada beberapa raja Islam untuk menjadi khalifah baru. Meraka terdiri daripada Raja Afganistan, Amanullah Khan yang melobi jawatan khalifah. Syarif Hussin Ali, Raja Hijaz telah dibai'ah oleh orang Palestin dan Jordan Timur. Raja Fuad dari Mesir turut merebut jawatan ini, sedangkan pada masa yang sama, Sultan Abdul Majid Wahiduddin, khalifah terakhir Daulah Othmaniyah yang berada dalam buangan di Malta berhasrat untuk terus menjadi khalifah umat Islam. Dalam suasana pergolakan inilah, terdapat beberapa usaha dilakukan termasuk mengadakan persidangan-persidangan untuk mengesahkan kekhalifahan yang baru. Persidangan Antarabangsa Khalifah ini dicadangkan oleh Sheikh Rashid Ridha (1865-1935M) dengan tujuan untuk menghimpunkan para ulamak dari semua wilayah umat Islam, bagi membincangkan langkahlangkah menubuhkan semula negara Islam dan melaksanakan syariat, sekali gus menjadi medan untuk memilih khalifah atau imam umat yang baru. 
Di Tanah Melayu pada 1920-an, turut tersebar juga idea-idea pergerakan khalifah dan kesedaran untuk menegakkan semula negara Islam. Malangnya, para ulamak di Tanah Melayu tidak mempunyai platform untuk bergerak, sehinggalah Sheikh Abbas Taha, iaitu Qadhi Besar Singapura, mencadangkan supaya sebuah 'Persatuan Ulamak Se-Tanah Melayu' yang bertaraf nasional ditubuhkan pada tahun 1931. Di Kelantan pula, beberapa siri perdebatan turut dianjurkan oleh Abdul Kadir Adabi bertujuan membahaskan keperluan menubuhkan 'Persatuan Ulamak Semenanjung'. Bagaimanapun cadangan-cadangan ini tidak berjaya kerana para ulamak di Tanah Melayu tidak pernah bertemu untuk melaksanakan gagasan ini. Keadaan ini sangat berbeza dengan para ulamak di Indonesia yang sering bermuktamar sejak muktamar pertama di Ceribon pada November 1922M dengan menggerakkan tindakan termasuk menubuhkan badan politik, iaitu sebuah organisasi masyarakat (ormas) dan gerakan khalifah melalui Congres Committee Chalifat (CCC). Ketika umat Islam di Indonesia sedang rancak bergerak, umat Islam di Tanah Melayu mulai bergerak kehadapan apabila Persaudaraan Sahabat Pena Malaya (PASPAM), sebuah kelab pembaca akhbar Saudara ditubuhkan pada 7 April 1934M dengan objektif untuk menggerakkan perjuangan melalui gerakan sastera dan bahasa Melayu. PASPAM yang mempunyai keahlian seluruh Tanah Melayu, Borneo, Sabah, Labuan dan Pattani telah mengadakan persidangannya yang pertama di Taiping pada 11 November 1934M, yang disebut oleh Profesor William Roff sebagai "perhimpunan orang-orang Melayu di Tanah Melayu yang pertama yang pertama" Setelah itu, PASPAM bersidang pula di Kuala Lumpur (1935M), Pulau Pinang (1936M), Singapura (1937M), Ipoh (1938M) dan Seremban (1939M).

Ternyata siri-siri persidangan ini berjaya memberi kesan besar kepada perubahan politik di Tanah Melayu. Namun, siri-siri persidangan telah terhenti akibat Perang Dunia Kedua. Pada zaman perang, kehidupan umat Islam menjadi lebih mencabar sehingga Dr. Burhanuddin alHelmy yang menjadi Penasihat Hal Ehwal Adat Istiadat Melayu di Gunseikanbu, pejabat tentera Jepun di Singapura menganjurkan Persidangan Ulamak Malai (Malaya) - Sumatera di Singapura pada 5-6 April 1943M melalui Pejabat Propaganda (Senden-Bu). Persidangan ini adalah pertama kali bagi para ulamak di Malaya. Pada 1944M, Dr Burhanuddin al-Helmy bertugas di Taiping dan sekali lagi dianjurkan Persidangan Majlis Agama Se-Malai pada 12-15 Disember 1944M di Kuala Kangsar. Impak besar hasil dua persidangan ulamak anjuran tentera Jepun ini kemudian mendorong Dr Burhanuddin al-Helmy mengarahkan Ustaz Abu Bakar al-Baqir menganjurkan Persidangan Agama di Gunung Semanggol pada 24 Mac 1947M yang berhasil menubuhkan Majlis Tertinggi Agama Malaya (MATA). Semasa Persidangan MATA yang diadakan pada 14 Mac 1948M, para ulamak telah berjaya menubuhkan Hizbul Muslimin, iaitu parti politik Islam yang pertama di Tanah Melayu. Namun begitu, Hizbul Muslimin tidak dapat bergerak lama kerana dilumpuhkan oleh Ordinan Darurat 1948 (Mohd Fadli, 2019).

Kesan daripada keruntuhan Hizbul Muslimin, para ulamak telah bergerak dalam Bahagian Agama UMNO sejak 1949M. Mereka membuat desakan kepada UMNO dalam perkara agama, akhirnya memaksa UMNO menganjurkan Persidangan Alim Ulamak Malaya di Muar pada 2122 Februari 1950M. Kegagalan UMNO melaksanakan resolusi para ulamak di Muar, kemudian menimbulkan kritikan keras para ulamak termasuk di dalam Suara UMNO sendiri. UMNO kemudian bersetuju menganjurkan Persidangan Alim Ulamak Malaya Kedua pada 23 Ogos 1951 di Kuala Lumpur. Dalam persidangan ini, para ulamak telah menubuhkan Persatuan Ulamak Malaya yang berasingan daripada UMNO (Mohd Fadli, 2019). 


\section{Permasalahan}

Turki merupakan negara yang mewarisi empayar besar Uthmaniyyah, yang mana segala perkara yang melibatkan negara itu, terutamanya dalam aspek politik akan memberi kesan terhadap seluruh dunia Islam (Abdar Rahman, 2017). Sebenarnya pengaruh Turki wujud dalam semua aspek kehidupan. Di Malaysia pengaruh itu wujud dan sentiasa berada dalam sudut pandang masyarakat Islam di negara ini. Pembangunan jati diri muslim misalnya, peribadi Sultan Muhammad Al-Fatih sering menjadi rujukan para ilmuan Islam dalam memberikan contoh terbaik (Abdul Latip, 2008). Dalam bidang pentadbiran, pemodenan Turki turut menjadi rujukan pemerintah di Malaysia (Mohd Ayob, 1915). Dalam bidang hiburan juga, pengaruh Turki tidak boleh dinafikan, filem Tiga Abdul arahan Tan Sri P. Ramlee memaparkan sebuah cereka yang berlatarkan Turki kepada masyarakat di negara ini (Ahmad Afiq, 2013). Dalam aspek seni bina di Malaysia turut terdapat pengaruh daripada Turki, perkara tersebut boleh dirujuk kepada seni bina Masjid Wilayah Persekutuan Kuala Lumpur (Masjid Wilayah Persekutuan, 2010). Melihat perkara tersebut, dirumuskan bahawa Turki sememangnya memberikan pengaruh yang begitu signifikan kepada masyarakat Malaysi secara langsung dan juga secara tidak langsung. Justeru itu, makalah ini akan membincangkan beberapa aspek yang mempunyai pengaruh Turki kepada sosiobudaya masyarakat Malaysia.

\section{Metodologi}

Secara umum, penulisan makalah ini berasaskan penelitian kandungan terhadap penulisan sarjanasarjana lepas mengenai kesan dan pengaruh Turki terhadap masyarakat Malaysia. Disamping itu juga, isu-isu semasa yang terbit dalam penulisan dan media turut menjadi data-data penting untuk diteliti. Pendekatan yang bersifat kualitatif ini sangat sesuai digunakan bagi memahami pengaruhpengaruh Turki terhadap sosiobudaya masyarakat tempatan.

\section{Pengaruh Dalam Aspek Siasah}

Pengaruh Islam sememangnya memberikan kesan yang sangat kuat terhadap siasah umat islam. Kerajaan Turki-Uthmaniyyah dilihat sebagai tempat bergantung seluruh umat Islam. Tambahan lagi penjajahan barat ke atas negara umat Islam di Alam Melayu menyebabkan orang Melayu telah memberikan harapan yang besar terhadap Turki-Uthnaniyyah bagi membebaskan negara umat Islam. Tedapat banyak misi dan utusan dihantar ke Istambul oleh raja-raja Melayu bagi meminta bantuan daripada Kerajaan Uttmaniah. Antaranya ialah Raja Ali Kelana Riau yang menghubungi kerajaan Turki-Uthmaniyyah agar membebaskan Alam Melayu pada Januari 1908. Namun begitu, usaha-usaha yang dilakukan oleh kerajaan Melayu gagal kerana keadaan Turki yang mulai lemah dan terlibat dengan perang Dunia Pertama dari tahun 1914 hingga 1918 (Hasanudin, 2003).

Kejatuhan kerajaan Turki-Uthmaniyyah telah menyuburkan budaya siasah politik organisasi di Tanah Melayu seawal tahun 1920-an. Kesedaran politik di Tanah Melayu sebenarnya telah disuburkan oleh golongan agamawan berikutan kejatuhan Turki-Uthmaniyyah. Pada tahun 1931, Kadhi Besar Singapura, Sheikh Abbas Taha mencadangkan supaya sebuah 'Persatuan Ulamak Se-Tanah Melayu' pada peringkat nasional ditubuhkan. Malah pada masa yang sama, Abdul Kadir Adabi daripada Kelantan telah menganjurkan beberapai siri kempen bahawa perlunya 
penubuhan sebuah organisasi Islam pada peringkat semenanjung. Golongan agamawan telah meniupkan semangat politik organisasi sebagai salah satu usaha menghidupkan kekhalifahan umat Islam sedunia. Usaha menghidupkan organisasi Islam agak terbantut akibat ketiadaan organiasi yang tersusun pada ketika itu. Perkara tersebut adalah akibat daripada penjajahan British yang mengawal ketat hubungan luar negara. Permualaan kepada gerakan siasah politik berlaku secara langsung melalui penubuhan Persaudaraan Sahabat Pena Malaya (PASPAM) pada 7 April 1934 dengan memperjuangkan sastera dan Bahasa Malayu (Mohd Fadli, 2019).

Perjuangan Tok Janggut atau nama sebenarnya Haji Hassan bin Panglima Mat Munas di Kelantan menentang pemerintahan British mempunyai hubungan yang dikaitkan dengan TurkiUthmaniyyah. Semasa Perang Dunia Pertama, Turki-Uthmaniyyah dan Jerman telah bersekutu menentang British di Eropah. Pada tarikh 5 November 1914, British mengisytiharkan perang terhadap Turki-Uthmaniyyah. Kemudian pada Pada 11 November 1914, kerajaan TurkiUthmaniyyah mengeluarkan fatwa yang dikenali sebagai Jihad-i-Ekbar Fard-I Ayon oleh Sheikh al-Islam, Khayri Effendi yang mengisytiharkan jihad terhadap British dan sekutunya (Farid, 2009). Jihad tersebut merupakan suatu tuntutan kepada seluruh umat Islam untuk menyokong TurkiUthmaniyyah. Seterusnya sesiapa yang memerangi Turki-Uthmaniyyah dan sekutunya adalah perbuatan yang berdosa. Turki yang merupakan sebuah negara Islam yang dipimpin oleh khalifah sangat dihormati dan mempunyai pengaruh yang besar, iaitu sebagai pelindung dan simbol penyatuan terhadap umat Islam. Jerman dalam hal ini telah menggunakan perisytiharan perang jihad tersebut sebagai propaganda penting dalam mendapatkan sokongan umat Islam.

Di Tanah Melayu, keberkesanan komunikasi propaganda Turki terhadap umat Islam dapat dilihat apabila perisytiharaan jihad oleh Turki mendapat sokongan penduduk yang beragama Islam. Seruan jihad berjaya membentuk semangat Pan-Islamisme, iaitu kesatuan umat Islam serantau untuk membenci dan bangkit menentang British. Perkara ini sememangnya membimbangkan British kerana masyarakat Islam seluruh dunia berpotensi untuk bangkit menentang British hasil daripada propaganda Turki dan Jerman yang berusaha membentuk semangat Pan-Islamisme (Hyson \& Lester, 2012). Seruan jihad tersebut disambut oleh golongan tentera India Muslim, iaitu Indian 5th Light Infantry dalam peristiwa yang dikenali sebagai Singapore Mutiny 1915 (Muhammad Aslah \& Mohd Samsudin, 2016). Regimen tentera tersebut telah bangkit memberontak pada 15 Februari 1915 di Singapura dengan menyerang pusat pentadbiran British dan membunuh penduduk warganegara British di Singapura. Penglibatan British dalam Perang Dunia Pertama dengan Turki dilihat merupakan faktor terbesar yang membawa kepada pemberontakkan kerana Turki-Uthmaniyyah dianggap ketua bagi seluruh umat Islam memberi sokongan terhadap Turki turut disambut oleh penduduk Melayu Muslim di Kelantan beberapa bulan selepas peristiwa Singapore Mutiny 1915. Kebangkitan di Kelantan yang dikenali sebagai Peasants Revolt tersebut dikaitkan dengan berita propaganda mengenai kejatuhan kerajaan British di Singapura. Terdapat juga propaganda bahawa tentera-tentera British telah meninggalkan Tanah Melayu untuk berperang di Eropah (Muhammad Aslah \& Mohd Samsudin, 2018; Cahyaningrum Dewojati, 2020). Reaksi orang Melayu terhadap perkara ini adalah pelbagai, ada yang menentang dan ada yang mengambil sikap tidak acuh. Perkara tersebut adalah disebabkan propaganda British yang licik dengan menggunakan pengaruh Sultan-sultan Melayu yang sangat ditaati oleh orang Melayu. Justeru itu, perjuangan Tok Janggut yang bermula pada 25 Mei 1915 mempunyai kesinambungan dan refleksi yang jelas terhadap hubungan persaudaraaan Islam antara Turki-Uthmaniyyah dengan Tanah Melayu.

e ISSN 2735 - 1904

https://doi.org/10.22452/JOMAS.vol32no1.4 


\section{Pengaruh dalam Urus Tadbir}

Kegemilangan kesultanan Johor banyak dipengaruhi oleh hubungannya dengan Khilafah Uthmaniyyah. Pada pertengahan tahun 1860-an, Sultan Abu Bakar dalam rangka lawatannya ke Eropah telah melawat Khalifah Uthmaniyyah di Istanbul. Hasil lawatan dan hubungan baik dengan kerajaan Turki-Uthmaniyyah tersebut, baginda kemudian telah diiktiraf sebagai Sultan Johor oleh Kerajaan Uthmaniyyah Turki mulai 13 Februari 1886. Baginda memakai gelaran Sultan dengan gelaran Sultan Abu Bakar Alkhalil Ibrahim Shah. Baginda juga telah dikahwinkan dengan wanita Turki yang mempunyai hubungan dengan istana khalifah. Hubungan Johor dengan Khalifah Uthmaniyyah amat akrab khususnya sejak tahun 1885, iaitu apabila Johor diperintah oleh Sultan Abu Bakar hinggalah tahun 1922 bawah pemerintahan Sultan Ibrahim. Beberapa buah bangunan khasnya istana-istana dan masjid-masjid dipengaruhi oleh bentuk-bentuk bangunan lama di wilayah Khilafah Uthmaniyyah (Abd Jalil, 2011).

Berdasarkan hubungan Johor dan Khilafah Uthmaniyyah yang begitu baik, dapat dikatakan bahawa Johor sebenarnya telah diperintah menggunakan sistem Khalifah, iaitu berada bawah naungan Khilafah Uthmaniyyah dan bukannya sistem British seperti yang di gambarkan dalam buku-buku sejarah. Ini dapat dibuktikan melalui Perjanjian Inggeris Johor Tahun 1885, dan dalam perjanjian tersebut Inggeris menganggap Johor sebuah negeri yang berdaulat dan merdeka kecuali dalam perkara yang berkaitan dengan hal ehwal luar yang diserahkan kepada Inggeris (Ronald Braddell, 1931). Dengan termeterainya perjanjian tersebut juga Inggeris telah mengiktiraf Maharaja Johor sebagai Sultan sebagaimana yang dikurniakan oleh Khilafah Uthmaniyyah bagi negeri dan jajahan Johor. Hal ini terkandung dalam Fasal ketujuh Perjanjian 1885:

"Bahawa sanya Yang Maha Mulia Maharaja Johor telah memberi ketahuan kepada Gabenor Strait Sattlement maksud orang besar-besarnya dan orangorangnya ialah baginya supaya memakai gelaran Sultan yang demikian diperjanjikan, iaitu pada menimbangkan persahabatan yang setia dan keadaan muhibbah." Sultan Abu Bakar telah menubuhkan sebuah lembaga penasihat yang bernama Jemaah Penasihat Johor yang ahli-ahlinya terdiri daripada sahabat-sahabat baginda sendiri.

(Buyong Adil, 1980)

Tindakan ini adalah merupakan bantahan secara tidak langsung yang dilakukan oleh Johor bagi meneruskan kedudukannya sebagai sebuah negeri yang merdeka (Abd Jalil, 2011). Bagi mengukuhkan lagi kedudukannya sebagai seorang pemerintah yang merdeka dan berdaulat, dalam tahun 1885 baginda telah menubuhkan Pasukan Askar Timbalan Johor bagi mempertahankan kesultanan Johor daripada dicabuli oleh kuasa-kuasa luar (Keith Sinclair, 1967). Struktur pentadbiran kerajaan negeri Johor juga dikatakan mempunyai negara-negara maju di bawah pemerintahan Khalifah Uthmaniyyah. Perkara ini diperkuat dengan penubuhan Pejabat Setiausaha Kerajaan, Jabatan Perbendaharaan, Pejabat Audit, Mahkamah Besar, Pejabat Percetakan Kerajaan, Jabatan Kerjaraya, Polis, Pejabat Ukur, Pejabat Tanah, Pejabat Pelajaran dan lainlain. Pentadbiran negeri dijalankan mengikut arahan baginda Sultan dan Majlis Mesyuarat Negeri serta dibantu juga oleh beberapa orang bangsa Eropah (Abd Jalil, 2011). 
Pemodenan Turki oleh Mustafa Kemal turut memberikan pengaruh yang cukup besar kepada pemodenan dan urus tadbir negara pada era pra-merdeka dan pasca-merdeka. Idea bahawa pemodenan yang memisahkan agama dengan pentadbiran seperti mana yang dibawa oleh Turkimoden turut menjadi sumber inspirasi golongan yang berpendidikan Inggeris. Acuan sekularisme inilah yang menjadi dasar perlembagaan negara yang dibuat berlandarkan acuan Inggeris (Abdul Basir, 2002). Pemimpin yang berfahaman barat berpendapat bahawa pemodenan Turki yang dipelopori oleh Kemal boleh menjadi model kepada perubahan negara Islam yang berasal daripada unsur tradisi kepada moden. Bagaimanapun penyebaran pengaruh sekularisme ini tidaklah berlaku secara langsung oleh Turki-moden, tetapi perkara ini dilakukan secara terancang oleh gerakan barat melalui penjajahan Inggeris di Tanah Melayu menerusi pengasingan istana dengan pentadbiran dan pemecahan sistem pendidikan yang berbeza. Ilmu agama hanyalah untuk aktiviti ibadat sematamata, manakala mata pelajaran lain tidak diterapkan unsur agama di dalamnya. Maka dalam masa yang panjang sistem sekular bertapak kukuh dalam aspek pentadbiran, ekonomi dan sosial (Abd Jalil, 2011). Fadhlullah (2011) pula menjelaskan, kemerosotan Kerajaan Uthmaniyyah selepas era Sultan Suleiman al-Qanuni adalah disebabkan berlakunya kepincangan dalam pentadbiran berikutan pengabaian terhadap pemerintahan yang berlandaskan syariat Islam. Justeru, sekularisasi dalam perundangan Turki merupakan satu episod yang penting dalam perkembangan sejarah Turki moden yang perlu dijadikan iktibar termasuklah dalam konteks negara Malaysia.

Mutakhir ini pengaruh Turki melalui pemimpinnya, iaitu Recep Tayyip Erdogan disanjung oleh ramai aktivis Islam sedunia termasuk Malaysia. Pembaharuannya yang dikatakan selaras dengan pendekatan Islam prakmatik menjadikan contoh kepada pemimpin parti politik Islam di Malaysia. Terdapat beberapa kumpulan dalam sebuah parti Islam di Malaysia diberikan jolokan "Erdogan" yang merujuk kepada gologan baharu agama yang progresis yang bertentangan dengan pemimpin yang berfikiran tradisional (Mohamad Fadli, 2016). Maszlee (2016) menghujahkan bahawa gerakan Islam pada abad moden merupakan kesinambungan kepada Khalifah Uthmaniyyah yang telah terbubar, iaitu perjuangannya pada peringkat awal menjurus kepada penegakkan semula khalifah, menentang penjajah yang secara umumnya terdiri dari negara-negara Barat serta menuntut kemerdekaan tanah air. Pada fasa ini juga, penentangan gerakan Islam terhadap kuasa kolonial bukan sahaja disebabkan oleh penjajahan wilayah yang dilakukan, akan tetapi turut melibatkan kritikan terhadap pengaruh pemodenan acuan Barat yang bercirikan rasional, empirikal dan sekular semata-mata ke atas dunia Islam. Erdoğan cuba memperkasakan agenda pendemokrasian dan mewujudkan wacana politik baru di Turki dengan mengambil pendekatan mentafsirkan semula sekularisme dari perspektif kebebasan dan hak asasi, membuka pintu bagi mewujudkan dialog dengan Barat melalui EU, tidak berkonfrontasi dengan elit sekular Turki serta membina penyelesaian baharu kepada permasalahan masyarakat berbanding terlibat dalam perdebatan ideologi. Di samping itu, nilai-nilai konservatif turut diberi perhatian dan diangkat melalui proses pendemokrasian (Muhammad Khalis dan Mohd Roslan, 2019).

Dalam kalangan sarjana, perkembangan terbaharu Turki moden wajar dijadikan pengajaran dalam pembangunan Islam di negara ini. Perkara yang pertama ialah komitmen Adalet ve Kalkınma Partisi (AKP) yang berjaya menzahirkan Islam di Turki dalam kekangan dan keterbatasan yang ada dalam perlembagaan Turki. Kedua, perlunya melestarikan pelaksanaan Islam dengan keadaan persekitaran semasa, disamping mengekalkan prinsip-prinsip tauhid Islam. Perkara ini menjadi faktor kejayaan AKP dalam menzahirkan Islam di Turki pada era moden. Ketiganya, wacana Islam di Turki banyak berkonsepkan kepada nilai praktikal berbanding dengan ideologi. Pemilihan 
pendekatan berasaskan nilai ini sangat relevan dan bersesuaian jika mengambil kira cabaran dalam konteks politik di Turki. Terdapat beberapa golongan di Malaysia yang cenderung menjadikan model AKP Turki sebagai model yang perlu dicontohi (Muhammad Khalis dan Mohd Roslan, 2018).

\section{Pengaruh dalam Seni}

Pengaruh sesuatu budaya terhadap budaya lain pastinya dapat dilihat dengan jelas dan boleh dirasai kewujudnya di persekitaran. Hasil seni serupakan salah satu bukti penting kewujudan sesuatu pengaruh. Masjid Wilayah Persekutuan Kuala Lumpur merupakan satu contoh terbaik dalam menyatakan hal ini. Reka bentuk seni bina dan hiasan dalamannya pula adalah merupakan kombinasi reka bentuk tradisi Melayu Malaysia dan menggunakan konsep tradisi masjid-masjid Uthmaniyyah di Turki.
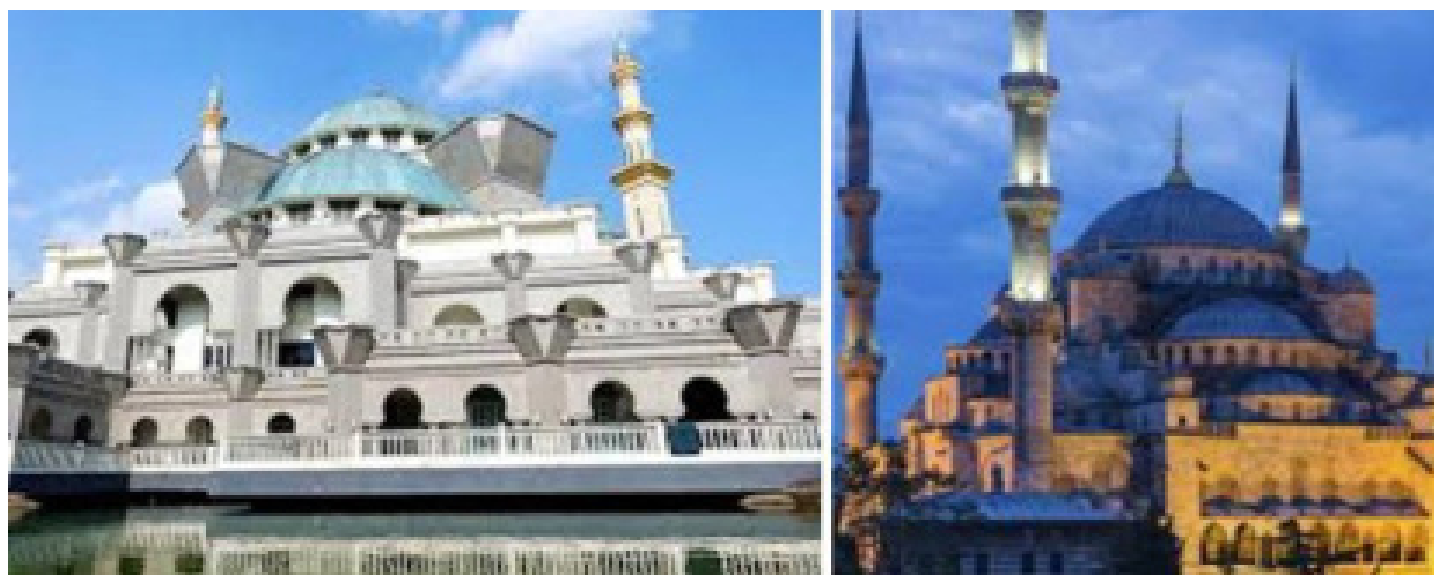

Sumber: Kajian lapangan 2020

Tulisan khat merupakan salah satu bukti kewujudan pengaruh sesuatu tamadun bangsa terhadap bangsa lain. Dalam konteks Alam Melayu, terdapat beberapa jenis tulisan khas yang berasaskan kepada Turki Uthmaniyyah. Tulisan khat tersebut ialah Khat Diwani, Khat Diwani Jali dan Khat Riq'ah. Khat Diwani ini dikembangkan oleh penulis, Ibrahim Munif. Kemudian, disempurnakan oleh Syaikh Hamdullah dan penulis pada zaman Khilafah Uthmaniyyah di Turki pada akhir abad ke-15 dan awal abad ke-16. Gaya ini digunakan untuk menulis kepala surat rasmi kerajaan asing. Ciri-ciri khat ini adalah bulat dan tidak berbaris. Keindahan tulisannya bergantung kepada permainan garisannya yang kadang-kadang pada huruf tertentu meninggi atau menurun. Model kaligrafi Diwani banyak digunakan pada seni bina dan sampul buku. Khat Diwani Jali pula merupakan pengembangan gaya Diwani. Gaya penulisan kaligrafi ini diperkenalkan oleh Hafiz Usman, seorang penulis terkemuka pada zaman Khalifah Uthmaniyyah di Turki. Anatomi huruf Diwani Jali pada asalnya mirip Diwani, namun jauh lebih berseni, padat, dan mempunyai corak bertitik-titik. Berbeza dengan Diwani yang tidak berbaris, Diwani Jali sebaliknya sangat padat dengan baris dan hiasan. Baris yang penuh ini lebih ditujukan untuk keperluan dekorasi dan tidak 
seluruhnya berfungsi sebagai tanda bacaan. Oleh sebab itu, gaya ini sukar untuk dibaca secara sepintas lalu. Biasanya, model ini digunakan untuk aplikasi pada seni bina masjid atau barangan hiasan. Khat Riq'ah pula merupakan hasil pengembangan kaligrafi gaya Nasakh dan Thuluth. Sebagaimana keadaannya dengan tulisan gaya Nasakh yang diguna-pakai dalam tulisan seharian. Riq'ah dikembangkan oleh penulis pada zaman Khalifah Uthmaniyyah digunakan untuk tulisan tangan biasa atau untuk kepentingan praktikal yang lainnya. Ciri-ciri hurufnya sangat sederhana, tanpa baris, membolehkan untuk ditulis dengan cepat (Iskandar, 2017).

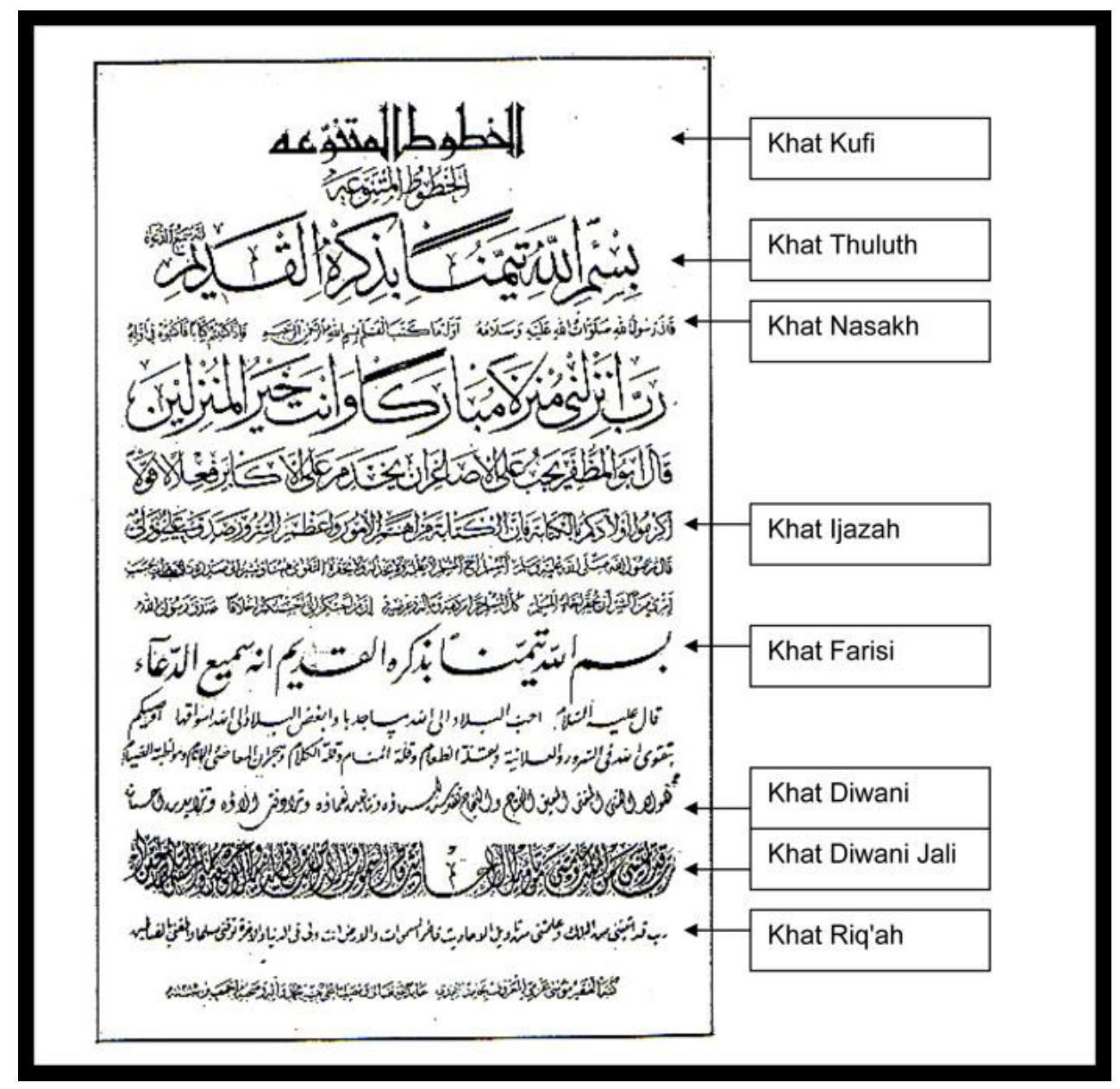

Gambar 1: Jenis-jenis tulisan khat

Sumber: Iskandar, 2017 


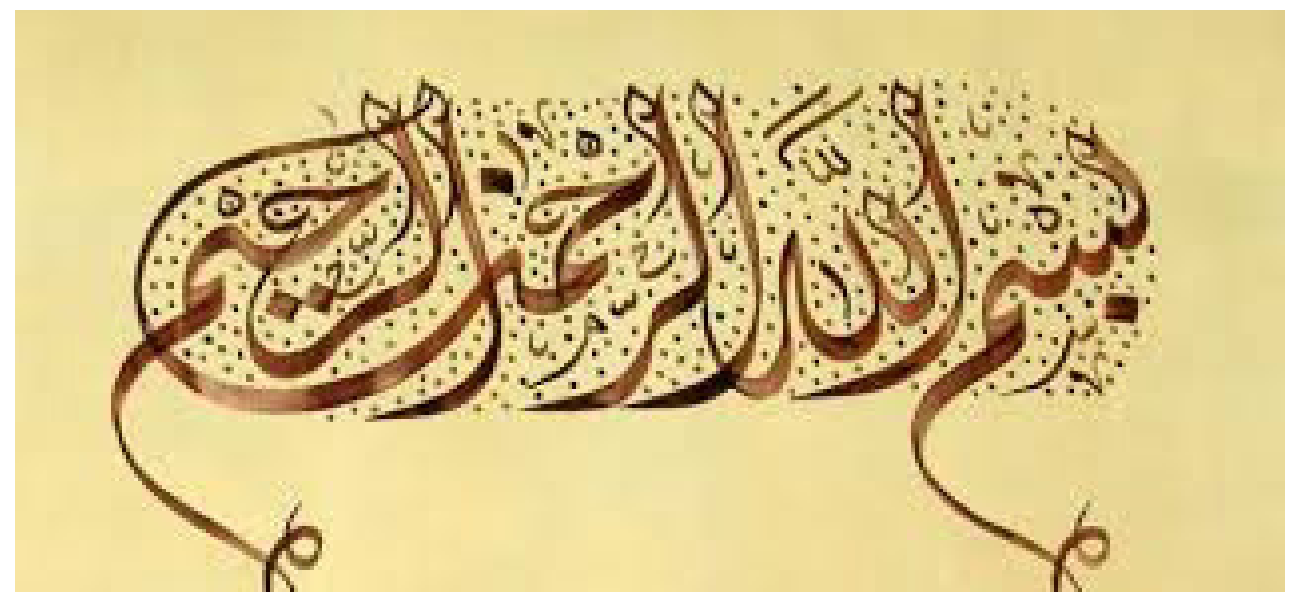

Gambar 2: Contoh Khat Diwani Jali

Sumber: Iskandar, 2017

Perkara yang ketiga dalam aspek seni ialah filem cereka. Filem Tiga Abdul arahan Tan Sri P. Ramle dan diterbitkan oleh Malay Flim Production pada tahun 1969 merupakan contoh terbaik bagi menunjukkan pengaruh Turki dalam seni lakon di negara ini. Dalam Filem tersebut, digambarkan naratif kejatuhan kerajaan Turki Uthmaniyyah semasa era 1823 hingga 1923. Dalam filem Tiga Abdul, Turki Uthmaniyyah digambarkan sebagai “The Sick Man" yang merujuk kepada masalah kewangan dan ekonomi yang dihadapi oleh empayar tersebut disamping kekalahankekalahan dalam peperangan sehingga kehilangan banyak wilayah. Empayar Uthmaniyyah juga terlibat dengan Treaty of Sevres (10 ogos 1920) yang mana negara-negara kuasa besar seperti British, Perancis dan Itali membahagi-bahagikan wilayahnya selepas kekalahan pada Perang Dunia Pertama (Daus Ishak, 2019). Filem tersebut, walaupun dipersembahkan secara jenaka, tetapi memberikan kesan yang cukup mendalam pada orang Melayu yang menghayatinya. 


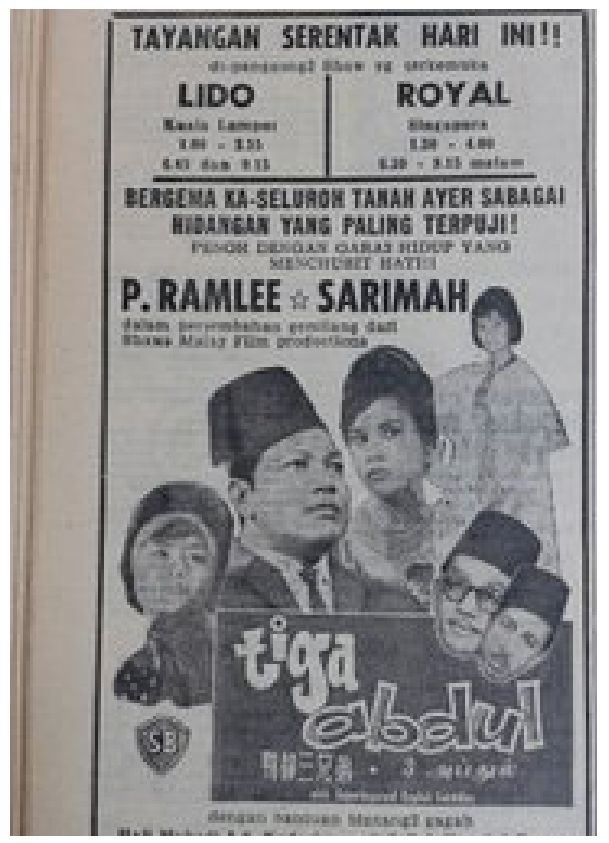

Gambar 3: Keratan Akhbar Iklan Filem Tiga Abdul

Sumber: Daus Ishak (2019)

\section{Pengaruh dalam Aspek Modal Sosial}

Pembangunan modal sosial merupakan salah satu elemen yang cukup penting bagi membangunkan sesebuah negara (Ahmad et al., 2018). Akhlak yang mulia disamping keteguhan iman dan ketaqwaan kepada Allah merupakan aset penting dalam pembinaan jati diri seseorang muslim. Akhlak yang mulia disamping ketaqwaan kepada Allah merupakan perkara yang penting bagi mendapatkan kejayaan di dunia dan akhirat. Abdul Latip (2008) menjelaskan bahawa kekuatan spiritual yang dimiliki oleh Sultan Muhamad Al-Fateh merupakan kunci utama kejayaan bagaimana baginda berjaya menakluki kota Konstantinopel pada tahun 1453M. Keperibadian yang mulia di samping ilmu pengetahuan yang cukup sebagai pemerintah menjadikan baginda pemerintah terbaik. Sultan Muhammad Al-Fateh semasa kecilnya telah berjaya menghafal Al-Quran, membaca hadith, belajar ilmu fekah, matematik, astronomi, dan urusan peperangan di samping belajar bahasa Arab, Parsi, Latin, Greek, Serbia, Turki, Parsi dan Hebrew. Kejayaan Sultan Muhammad Al-Fateh menakluk Konstantinopel telah berjaya mencapai satu prestij dalam sejarah perkembangan dahwah Islam, selain mendapat faedah strategi ketenteraan dan faedah ekonomi terutamanya melalui perdagangan rempah (Ahmad et al., 2018). Ketokohan baginda (sultan Muhammad Al-Fateh) kerap dijadikan contoh bandingan oleh pendakwah, pakar motivasi dan penulis-penulis supaya dijadikan personaliti ikutan kepada generasi hari ini. Keazaman yang ditunjukkan oleh baginda di samping ketakwaan kepada Allah dijadikan sebagai bahan modal sosial oleh pelbagai pihak.

Tidak cukup dengan contoh pada zaman kegemilangan Turki-Uthmaniyyah sahaja, zaman pra-kejatuhannya juga dijadikan bahan modal sosial kepada generasi muda di Malaysia (Mohammad Auni, 2019). Zaman era pemodenan Turki, iaitu pada zaman pemerintahan Kemal turut dijadikan contoh bandingan kepada umat Melayu di Malaysia (Abdar Rahman, 2017). Ketokohan Recep 
Tayyip Erdogan yang menyulam elemen Islam dalam sistem sekular turut menjadi modal kepada pembinaan modal sosial yang baik di Malaysia. Ramai tokoh politik Islam di Malaysia menjadikan beliau ikon pembaharuan dan model untuk gerakan siasah parti politik, walaupun ada sarjana yang berpendapat bahawa suasana politik dan latar belakang sosial antara Turki dan Malaysia adalah berbeza (Muhammad Khalis dan Mohd Roslan, 2018).

\section{Pengaruh dalam Aspek Identiti}

Bendera merupakan lambang dan identiti negara. Kekhalifahan Turki-Uthmaniyyah mempunyai pengaruh yang cukup besar kepada seluruh negara-negara Islam di dunia. Perkara tersebut boleh dilihat kepada persamaan-persaman bendera negara-negara Islam pada hari ini. Di Malaysia, terdapat beberapa negeri yang benderanya mempunyai persamaan yang jelas. Gambar 4 pula adalah bandingan bendera Turki dengan bendera negeri Johor, Kelantan, Selangor dan Terngganu. Pada bendera negeri Kelantan, terdapat pertambahan imej, iaitu tambahan dan keris yang menjadi lambang tempatan yang merupakan identiti setempat, iaitu senjata Melayu.

Sementara itu, bagi identiti personaliti orang Melayu, iaitu songkok dan kopiah juga dilihat mempunyai persamaan yang jelas. Foto 6 merupakan imej yang terdiri daripada Tarbus (Turki) dan Songkok serta Kopiah yang menjadi pakaian rasmi (Songkok). Songkok dan tarbus ini mempunyai persamaan yang ketara. Persamaan ini berlaku akibat hubungan yang rapat antara Sultan Melayu dengan Kerajaan Turk-Uthmaniyyah pada masa dahulu (Abd Jalil Borham, 2011). Imej dan simbol ini amat penting dalam menghasilkan pengaruh dan kesan ingatan terhadap orang ramai (Marzudi et al., 2019).

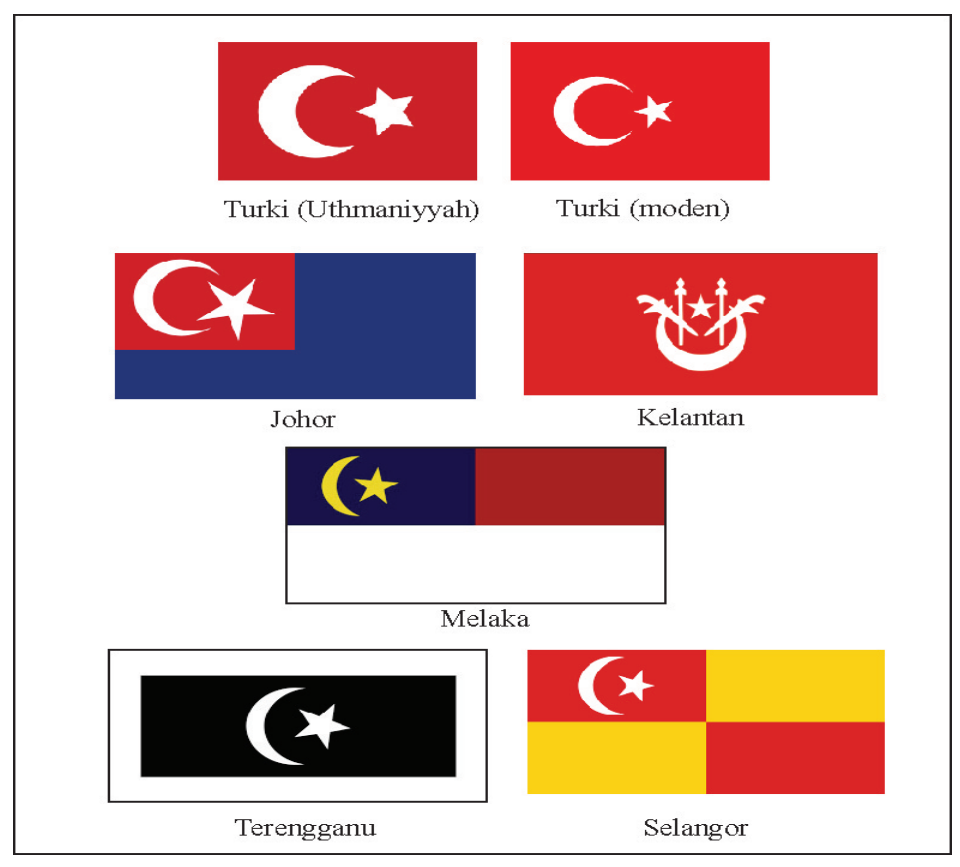

Gambar 4: Antara negeri di Malaysia yang mempunyai persamaan

Imej bulan-bintang seperti bendera Turki

Sumber: Kajian lapangan 2020 


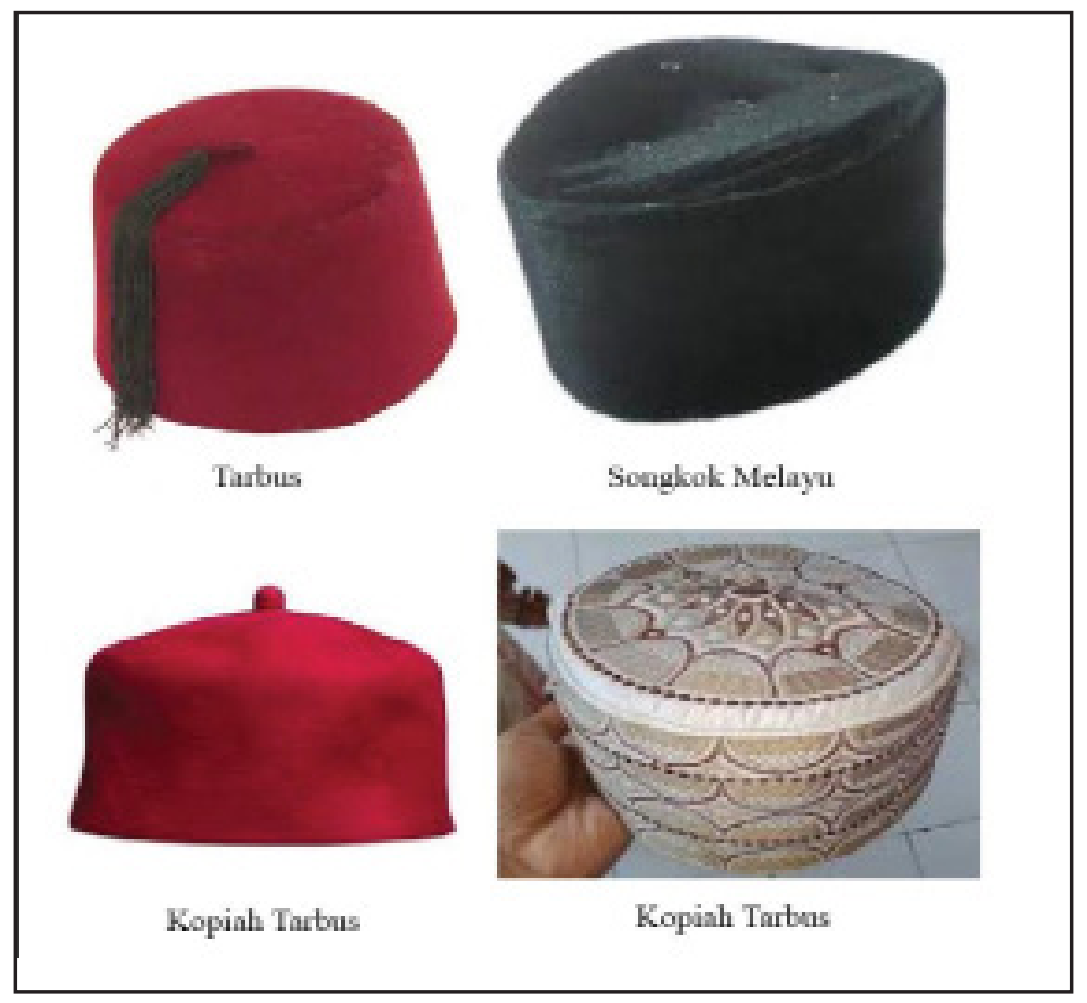

Foto 2: Penutup kepala Turki-Melayu

Sumber: Kajian lapangan 2020

\section{Kesimpulan}

Hubungan yang terjalin antara Alam Melayu dengan Turki Uthmaniyyah telah membawa kesan yang cukup besar kepada aspek siasah, pentadbiran, dan sosiobudaya. Hubungan itu bukan sahaja berlaku dalam konteks penaung dengan negeri di bawah naungan semata-mata, tetapi berdiri atas persaudaraan Islam dan juga tanggungjawab. Khalifah Turki Uthmaniyyah berperanan sebagai pemimpin umat Islam yang berperanan mengetuai umat Islam selepas kewafatan Nabi Muhammad SAW. Alam Melayu pula sebagai negeri bawah naungan khalifah meletakkan taat setia dan menyanjung tinggi institusi tersebut. Hubungan semasa era kekhalifahan dilihat lebih signifikan dalam pembinaan pengaruh Turki di Alam Melayu. Perkara tersebut dapat dibuktikan dengan wujudnya hubungan yang bersifat erat dan peribadi berikutan wujudkan perkahwinan Diraja dan penghantaran utusan dan pendakwah di Alam Melayu yang secara tidak langsung membina ketamadunan yang mempunyai kesinambungan antara dua kerajaan. Sistem kekhalifahan itu sendiri sebenarnya yang mewujudkan persamaan identiti yang bersifat ketatanegaraan dan pentadbiran. Pemodenan negari Johor merupakan bukti jelas pengaruh Turki terhadap perkembangan sejarah di Alam Melayu. Begitu juga halnya dalam pembinaan simbol negara dan kedaulatan. Bendera yang menjadi simbol kepada kedaulatan jelas mempelihatkan kekuatan pengaruh Turki-Uthmaniyyah di Alam Melayu. Perkara tersebut memperlihatkan bahawa daulah Islamiyah akan terus kekal di Alam Melayu. Bagaimanapun hubungan yang berterusan antara Tanah Melayu-Turki Uthmaniyyah dan 
Turki moden terbantut akibat daripada beberapa faktor yang memberi kesan yang cukup besar seluruh umat Islam. Faktor-faktor tersebut ialah Perang Dunia Pertama yang membawa kepada merosotnya kuasa Turki-Uthmaniyyah. Terhapusnya sistem kekhalifahan juga merupakan faktor yang mendorong hubungan yang berterusan dengan Tanah Melayu secara langsung. Bagaimanapun faktor-faktor tersebut tidak menghalang kesinambungan pengaruh Turki-Uthmaniyyah dan TurkiModen terhadap sosiobudaya di negara ini. Pengaruh-pengaruh tersebut turut dapat dilihat secara visual dan bentuk seni bina, seni tampak (khat), pendekatah siasah politik yang rakmatik dan juga perkembangan modal insan yang ketara.

\section{Rujukan}

Abd Jalil, Borhan. (2011). Pengaruh Khilafah Othmaniyyah Turki dalam pentadbiran Kerajaan Johor bagi memartabatkan sebuah negara Islam merdeka di Asia Tenggara. 12 April 2011. $\quad$ Simposium Isu-Isu Sejarah dan Tamadun Islam (SISTI 2011) Peringkat Kebangsaaan, Universiti Kebangsaan Malaysia, Bangi, Selangor.

Abd. Jalil Borhan. (2011). Pengaruh Khilafah Othmaniyyah Turki dalam pentadbiran Kerajaan Johor bagi memartabatkan sebuah negara Islam merdeka di Asia Tenggara. 8-10 April 2011. Kertas kerja Ucaptama Simposium Isu-isu Sejarah dan Tamadun Islam (SISTI 2011) Peringkat Kebangsaaan di Sudut Wacana ATMA, Universiti Kebangsaan Malaysia, Bangi, Selangor.

Abdar Rahman Koya. (2017). Kebisuan puak 'Erdogan' di Malaysia. 16 Mei 2017. Retrieved from https://www.freemalaysiatoday.com/category/opinion/2017/05/16/kebisuan-puakerdogan-di-malaysia/.

Abdul Basir Alias. (2002). Ancaman nasionalis sekular ekstrim di Malaysia: Satu kajian

Ilmiyah. Bangi, Selangor: AS-Syabab Media.

Abdul Latip Talib. (2008). Sultan Muhammad Al-Fateh - Penakluk Konstantinopel. Batu Caves, Selangor: PTS Publications \& Distributors Sdn Bhd.

Abu Hanifah Haris \& Mohammad Redzuan Othman. (2011). “Kemal Ataturk dan pembaharuan di Turki: Polemik dalam akhbar dan majalah melayu pada tahun 1920-an dan 1930 an”. Jurnal Sejarah, 19, No.19, 104-133.

Ahmad Afiq Al-Kelantani. (2013). Rahsia di sebalik filem “Tiga Abdul”. Retrieved from http:// amgdot786.blogspot.com/2013/10/rahsia-di-sebalik-filem-tiga-abdul_6647.html.

Ahmad Azan Ridzuan, Noor Azmi Hj Mohd Zainol, Jessica Ong Hai Liaw, Norlaila Mazura Mohaiyadin \& Safar Yaacob. (2018). Dimensi-dimensi kejayaan sultan Muhammad Al-Fateh sebagai arkitek penaklukan Kota Konstantinopel. 23-24 April 2018. e-Prosiding Persidangan Antarabangsa Sains Sosial dan Kemanusiaan/Kolej Universiti Islam Antarabangsa Selangor, Kajang, Selangor.

Buyong Adil. (1980). Sejarah Johor. Kuala Lumpur: Dewan Bahasa dan Pustaka. 
Cahyaningrum Dewojati. (2020). Persaingan ideologi dan muatan propaganda dalam drama semasa pendudukan Jepun di Indonesia. Jurnal Pengajian Melayu/Journal of Malay Studies (JOMAS), 31(2020), 1-19.

Daus Ishak. (2019). Filem Tiga Abdul Penuh dengan rahsia yang mempunyai mesej tersirat padat dengan pengajaran. 15 Januari 2019. Retrieved from https://siakapkeli. my/2019/01/15/filem-tiga- abdul-penuh-dengan-rahsia-yang- mempunyai-mesejtersirat-padat-dengan-pengajaran $/$.

Ermy Azziaty. (2016). "Manuskrip 'Hikayat Perang Setambul' dan 'Hikayat Peperangan Al- Maulana Sultan Istanbul yang bernama Abdul Hamid Khan1: Sejarah Peperangan Daulah Turki Uthmaniyah dan Rusia," Jebat: Malaysian Journal of History, Politics \& Strategic Studies, 43, No. 2, 23-50.

Fadhlullah Jamil. (2007). Islam di Asia Barat moden: Penjajahan dan pergolakan. Shah Alam, Selangor: Karisma Publications.

Hamka. (2016). HAMKA: Sejarah umat Islam. Batu Caves, Selangor: PTS Publishing House.

Hasanudin. (2003). "Sejarah hubungan ulama-umarak: Pengalaman Syeikh Ahmad Bin Muhammad Zain Al-Patani (1856-1908). Jurnal Sejarah, 11, No.11, 3-14.

Hyson, S., \& Lester, A. (2012). "British India on trial: Brighton military hospital and the politics of empire in world war I, ” Journal of Historical Geography, 38, No.1, 19-34. Iskandar (2017) Pengenalan Jenis-Jenis Khat Tersohor. Dimuat turun daripada https://www.facebook.com/kufistoreseriiskandar/posts/pengenalan-jenis-jenis-khattersohor-khat-kufi-kaligrafi-gaya-kufi-penulisannya-/770368443151609/.

Jay Shaw, Stanford. (1977). History of the Ottoman Empire and modern Turkey. London: Cambridge University Press.

Keith Sinclair. (1967). "The British Advance in Johore 1885-1914," Journal of the Malaysian Branch of the Royal Asiatic Society, 40, No. 1, 93-110.

Marzudi Md Yunus, Nur Yuhanis Mohd Nasir \& Nurul Haniza Samsudi. (2019). Logo Hari Kebangsaan 2018: Analisis Teori Seni dan aplikasi Komunikasi Visual. Jurnal Komunikasi: Malaysian Journal of Communication, 35(2), 176-194.

Masjid Wilayah Persekutuan. (2010). Konsep dan reka bentuk bangunan Masjid Wilayah Persekutuan. Retrieved from http://www.masjidwilayah.gov.my/index. php/ profail/konsep-rekabentuk-bangunan.

Maszlee Malik. (2016). Pasca-Islamisme atau wacana baru Gerakan Islam? Dalam generasi kedua politikal Islam Wacana Baru Gerakan Islam Jilid 1. Nilai, Selangor: Ilham Books.

Mohamad Fadli. (2016). Kita cuma ikut contoh baik erdogan, kata pemimpin amanah. 27 Ogos 2016. Retrieved from https://www.freemalaysiatoday.com/category/bahasa/2016/08/07/ kita-cuma-ikut-contoh-baik-erdogan-kata-pemimpin-amanah/-.

Mohd Ayob Abd Razid. (1915). Kesultanan Johor pencetus amalan birokrasi moden. Retrieved from https://www.bharian.com.my/node/44028. 
Mohd Fadli Ghani. (2019). Memori muktamar sempena muktamar tahunan PAS kali ke-65 kejatuhan Khalifah, Persidangan Ulamak dan Perpaduan Umat. 28 Mei 2019. Retrieved from https://berita.pas.org.my/memori-muktamar-kejatuhan-khalifah-persidanganulamak-dan-perpaduan-umat/.

Muhammad Aslah Akmal Azmi \& Mohd Samsudin. (2016). Keberkesanan pentadbiran British mengekang Singapore Mutiny 1915: Satu analisis. 12 Ogos 2016. Seminar Antarabangsa ke-4 Arkeologi, Sejarah dan Budaya di Alam Melayu/ Universiti Kebangsaan Malaysia Bangi, Selangor, Malaysia.

Muhammad Aslah Akmal Azmi \& Mohd Samsudin. (2018). Propaganda British di Tanah Melayu pada zaman Perang Dunia Pertama (1914-1916). Jurnal Komunikasi Malaysian Journal of Communication, 34, No. 4, 19-41.

Muhammad Khalis Ibrahim \& Mohd Roslan Mohd Nor. (2019). Perkembangan Islamisasi di Turki Era Erdoğan (2002-2010): Pendekatan, Usaha dan Cabaran. Akademika, 89, No.1, 45-55.

Muhammad Khalis Ibrahim \& Mohd Roslan Mohd Nor. (2018). "Perkembangan Islam di Turki menerusi Pendekatan Politik". In "Penyelidikan Serantau Islam Dan Alam Melayu”, pp. 181-196, Kuala Lumpur: Akademi Pengajian Islam, Universiti Malaya.

Ralph Patrick. (1963). "Culture and behavior: Collected essays of Clyde Kluckhohn," Social Forces, 42, No.1, 121-123.

Ronald Braddell. (1931). The Legal Status of the Malay States. Stamford Road, Singapore: Malaya Publishing House Limited.

Siti Ainum Amijudin. (2020). Kesan kejatuhan Khalifah Uthmaniyyah terhadap umat Islam. Retrieved from https://www.Academia.Edu/32358247/Kesan_Kejatuhan_ Khilafah_Uthmaniyyah_Terhadap_Umat_Islam?

Wadad Kadi and Aram A. Shahin. (2013). "Caliph, Caliphate". The princeton encyclopedia of Islamic political thought. New Jersey: Princeton University Press. 